\title{
Brasília nos filmes da Novacap
}

\section{Brasilia in movies Novacap}

\author{
Ana Lúcia de Abreu Gomes
}

Professora adjunta do curso de Museologia da Faculdade de Ciência da Informação da Universidade de Brasília

\section{Resumo}

Com este artigo, pretende-se apresentar uma possibilidade de leitura dos cinejornais produzidos durante a construção de Brasília e as implicações desse exercício de leitura para construção da imagem da capital brasileira em seus anos subsequentes. Por meio da análise dos filmes - que contaram com apoio do Estado pelo Decreto 21.240 de 1932 -, o texto leva a refletir sobre o processo político de construção de uma capital moderna para o Brasil. As abordagens teórico-metodológicas, no que se refere ao uso de imagens como fontes para a construção do conhecimento histórico, indicam a importância de dar a conhecer os processos que geraram determinado conjunto documental.

Palavras-chave: cinejornais, construção de Brasilia, uso de imagens

\section{Abctract}

With this article, we intend to present an interpretatios posibility of newsreels produced during the construction of Brasilia and the implications of this reading exercise for building the image of the Brazilian capital in their subsequent years. Through the analysis of the films - which had the support of the State Decree 21,240 1932 - the text leads to a reflection on the political process of building a modern capital for Brazil. The theoretical and methodological approaches, with regard to the use of images as sources for the construction of historical knowledge, indicate the importance of publicizing the processes that generated particular set of documents.

Keywords: newsreels, construction of Brasilia, use of imag 
Proponho, aqui, nesse Simpósio Temático sobre As cidades de cada dia: olhares sobre a cidade moderna, refletir sobre o processo político de construção de uma capital moderna para o Brasil: Brasília, uma cidade que no final dos anos 1950 já existia sem ter sido construída. Escolhi fazê-lo por meio da análise de filmes produzidos oficialmente, os chamados cinejornais que, no Brasil passaram a contar com o apoio do Estado por meio do decreto 21.240 de 1932. Por meio deste instrumento legal, antes dos filmes de longa-metragem era obrigatória a apresentação de um informativo de cerca de dez minutos. Essas características levaram a uma abordagem do cinejornal como uma forma de jornalismo por meio da experiência estética do cinema. (MAIA, 2006: 09)

Alguns historiadores já debruçaram de forma bastante competente sobre as vinculações dos cinejornais da Novacap com o Governo Juscelino Kubitscheck (RODRIGUES, 1996; BIZELLO, 2008) explorando a dimensão de propaganda do governo durante os pouco mais de três anos de construção da nova capital. Meu objetivo com este presente artigo, portanto, é de outra natureza: pretendo apresentar uma possibilidade de leitura dos cinejornais produzidos durante a construção de Brasília e as implicações desse exercício de leitura para construção da imagem de Brasília em seus anos subsequentes.

As abordagens teórico-metodológicas, no que se refere ao uso de imagens como fontes para a construção do conhecimento histórico, nos indicam a importância de dar a conhecer os processos que geraram determinado conjunto documental: suas condições sociais de produção, circulação e recepção. Isto porque a produção e circulação tanto de textos quanto de imagens são sustentadas por determinados processos e agentes sociais que, em seu cotidiano, elaboram textos orais, escritos, imagéticos, mobilizando uma série de princípios estéticos, retóricos, argumentativos no curso de sua interação social.

Sobre as condições de produção desses cinejornais, é importante ressaltar que no início dos anos 1980, a Fundação Nacional pró-Memória elaborou um catálogo específico sobre os cinejornais produzidos pela Novacap para documentar a construção de Brasília. A feitura do catálogo era uma forma de proteger e veicular esse conjunto de filmes que tratavam do período da construção da nova capital. Além da decupagem dos cinejornais, a Fundação Nacional pró-Memória transcreveu um conjunto de entrevistas com os cinegrafistas responsáveis pela filmagem de parcela desses filmes, o Sr. José Silva ${ }^{1}$ e o Sr. Sálvio Silva. O texto do catálogo que introduz este conjunto de entrevistas afirma:

Em 1957, sendo Israel Pinheiro o presidente da Novacap, a firma 'Libertas Filme', de Belo Horizonte, formada pelos cinegrafistas e sucessivamente transformada em 'Alvorada Filmes' e 'S.S.S. Produções', foi contratada para filmar o andamento dos trabalhos da construção da Nova Capital.”(ALVIM, s/d: 47).

Outras produtoras também foram contratadas para a produção de filmes, como é o caso da firma de Jean Manzon, a firma carioca Persin Perrin Produções ${ }^{2}$, a firma paulista Produções Cinematográficas Leides Rosa, a gaúcha Brasfilm, além, é claro da própria Agência Nacional.

Todo esse esforço e gasto financeiro com a produção de filmes é esclarecido com o depoimento de Sálvio Silva, filho de José Silva, ao relatar um episódio ocorrido em 1958 após a produção do primeiro filme colorido sobre a construção de Brasília. Ele conta que Israel Pinheiro o procurou determinando que ele exibisse o referido filme em Minas Gerais. Ainda segundo o cineasta, havia muita pressão contrária à construção de Brasília e era necessário então divulgar o que estava sendo feito. Sávio Silva afirmou então ter feito projeções em várias cidades de Minas Gerais. Segundo suas informações, havia uma política de exibição dos filmes firmada entre a Novacap e a União Cinematográfica Brasileira ${ }^{3}$, empresa responsável pela distribuição de parte significativa dos filmes que eram apresentados no país.

1 José Silva obteve um cargo de funcionário público do governo mineiro por meio de sua amizade com Israel Pinheiro, onde exerceu o cargo de Chefe de Diversões Públicas do Estado. Cf. RODRIGUES, 1990: 97.

2 Responsável técnica pela produção do documentário "As primeiras Imagens de Brasília".

3 A União Cinematográfica Brasileira (UCB - Distribuidora de Filmes) foi criada em 1945 e era propriedade do Grupo de Empresas da família Severiano Ribeiro. A UCB foi a mais influente distribuidora de filmes nacionais até o final da década de 70 do século passado. 
Há, também, nas cartas encaminhadas ao presidente JK, diversos pedidos específicos de cópias de filmes para serem veiculados pelo Brasil. É o caso da correspondência de um missivista fluminense que argumenta que nem todos têm acesso à revista ou ao cinema e solicita ao presidente Juscelino “(...) arranjar para passar [na sua região] o filme que amostre (sic) sobre a estrada Belém Brasília e sobre a construção da capital.” Ele assume a responsabilidade de exibir o filme ao ar livre para “(...) operários e pequenos lavradores que ficarão tão entusiasmados quanto eu." (NEIVA, 2008: 204)

Neste texto transcrito acima, pode-se inferir que a despeito da falta de infraestrutura elétrica para a instalação de cinemas em inúmeros municípios e localidades do país, havia uma assistência significativa aos cinejornais da Novacap, até porque a veiculação de curta-metragens nacionais era regulamentada por legislação correspondente como já citado.

A Revista Brasília também dá notícia da veiculação de filmes no exterior. $\mathrm{Na}$ revista $\mathrm{n}^{\mathrm{o}} 20$, de agosto de 1958, pode-se encontrar na página 16 a seguinte referência:

\section{Filmes em Lisboa}

Perante numerosa assistência, figuras de relevo da sociedade portuguesa e do governo, o Escritório Comercial do Brasil nesta capital exibiu no salão de projeção da residência do industrial João Rocha dos Santos o filme: "As Primeiras Imagens de Brasília”. (Revista Brasília, 1958: 16)

E mais, quando o entrevistador da Fundação Nacional Pró-Memória pergunta sobre a ausência nos filmes de operários e pessoas comuns em detrimento das autoridades, Sávio Silva esclarece os objetivos de um cinejornal: "Era um jornal de tela, de atualidades, e a preocupação era, realmente, oficial.” (Idem)

Não sabemos ao certo o número de cinejornais que foram produzidos pela Novacap. Há uma estimativa entre 24 e 38 cinejornais. Dos 24 a que tivemos acesso, todos eram em preto e branco com duração variável de 5 a 15 minutos. Os de 15 minutos se referem às comemorações do aniversário de Juscelino Kubitschek (Brasília no 20) e às festividades de inauguração da Nova capital (Brasília no 23). Além desses dois cinejornais, outros 3 versavam sobre temas específicos: o Brasília $n^{\circ} 01$ registrava aspectos da Primeira Missa em Brasília, produzido pela Libertas Filme com duração de dez minutos, o Brasília $n^{\circ} 5$, dedicado à visita do presidente de Portugal a Brasília, também da Libertas Filme, com duração de oito minutos; o de no 16 é totalmente dedicado às comemorações do $1^{\circ}$ de maio em Brasília, produzido pela Alvorada Filmes com 11 minutos de duração; o de no 19 com 5 minutos dedicado ao $1^{\circ}$ aniversário da Base Aérea de Brasília; o 21 e o 22 dedicados a mostrar aspectos da produção e do abastecimento de Brasília, ambos com dez minutos.

Em entrevistas recolhidas pelo Arquivo Público do Distrito Federal em seu Programa de História Oral, Sálvio Silva nos informa que os filmes eram editados com frequência, o que pode ser constatado por meio da significativa repetição de cenas em vários desses cinejornais. Avalio que se possa estimar que pelo menos 50\% das imagens dos cinejornais consultados sejam repetidas reiteradas vezes, só variando a locução. Por isso, e este é outro aspecto importante a se ressaltar, as imagens, nesses cinejornais, não necessariamente aparecem vinculadas à locução. Elas têm uma independência em relação à narração que cabe ser estudada. Sabe-se que havia muitas dificuldades técnicas para a captação direta de som. Segundo José Walter Nunes (2005: 56), apenas no final dos anos 1950 e início dos 1960 é que o gravador NAGRA já se encontra disponível no mercado. Portanto, os cinejornais desse período têm apenas locução. No caso dos discursos de Juscelino ou de outra autoridade, o profissional responsável pela locução do filme é que narra a fala presidencial, como no caso do Brasília no 16 em que todo o discurso de JK no primeiro de maio é repetido, na íntegra, pelo narrador.

O uso das produções cinematográficas, demonstrado pelo depoimento dos cineastas contratados pela Novacap, é clara: a imagem é capaz de retratar a realidade e, portanto, aquilo que é filmado e depois apresentado é tomado pelo que realmente aconteceu. O filme - assim como a fotografia, como imagens técnicas que são - está associado ao seu referente, possuindo, assim, um caráter indiciário, ou seja, a marca que uma presença deixou na película quer fotográfica, quer cinematográfica. Além deste aspecto, e talvez por causa dele, é muito comum tomar as narrativas, a organização disposta pela narrativa visual como inscrita na própria lógica do mundo, da realidade, como se ela existisse independentemente do homem que lhe atribui sentido.

E mais, afora esta crença há como que um acordo tácito entre espectadores de um filme que se pre- 
tende documentário e aquele que o produziu: se vou ao cinema para ver um documentário, está implícito que aquilo que verei realmente aconteceu, diferente de um filme de ficção por exemplo. Nas palavras de João Moreira Salles:

Diante desses filmes, realizador e espectador estabelecem um contrato pelo qual concordam que tais pessoas existiram, que disseram tais e tais coisas, que fizeram isso e aquilo. São declarações sobre o mundo histórico, e não sobre o mundo da imaginação. Para que o documentário exista é fundamental que o espectador não perca a fé nesse contrato. (SALLES, 2005: 58)

Portanto, o documentário - e aqui especificamente o cinejornal — já pressupõe que se a empresa produtora e a que veicula dizem que aquilo é um cinejornal, este fato já determina as expectativas daquele que irá ver o filme. Lembremos a singela associação entre documentário e documento como prova de uma determinada realidade. Paulo Menezes, nessa mesma linha, nos adverte também que

(...) para a esmagadora maioria do público, mesmo o versado nas lides das ciências sociais e das teorias do cinema e comunicações, o filme é uma expressão do real, mais ou menos fiel, mas sempre real, o que não deve de nenhuma maneira ser desprezado se tentarmos pensar o cinema e o filme documental como elementos da cultura e expressão das formas, conceitos e preconceitos com os quais construímos o mundo e nos posicionamos dentro dele. Não podemos nos esquecer, neste momento, do alerta que nos fez Bazin e que a mente culta costuma não encarar com seriedade que mereceria. ' $\mathrm{O}$ fenômeno essencial na passagem da pintura barroca à fotografia não reside em um simples aperfeiçoamento material [...], mas em um atributo psicológico: a satisfação completa de nosso apetite pela ilusão por uma reprodução mecânica da qual o homem está excluído. A solução não estava no resultado, mas na sua gênese'. O que ele aqui ressalta, em consonância com Merleau-Ponty, é que esse pressuposto psicológico da percepção é anterior ao que podemos sobre o filme pensar. É com esse pressuposto que vamos ao cinema. Pensamos sobre o filme depois. E é antes deste lapso temporal, evidentemente maior para uns do que para outros, que os mecanismos de ilusão cinematográfica se instauram e constituímos os primeiros sentidos a partir das provocações que as imagens do filme nos sugerem. (MENEZES, 2005: 81)

Portanto, textos, filmes, fotografias, depoimentos orais só adquirem significado quando se afere a sua possibilidade efetiva de verossimilhança e interação com o real (RICOEUR, 1997: 329), ou seja, só quando fazem sentido. Sendo assim, vejamos:

Após a assistência atenta dos cinejornais aqui apresentados, creio não ser equivocado dizer que tanto em sua narrativa imagética como textual eles se organizam de forma a apresentar um determinado antes e um depois. À medida que as obras avançam esse depois as acompanha.

Destacaria, neste momento o cinejornal Novacap número 10 por dois aspectos: primeiramente chamo a atenção para a locução final do vídeo que traz explicitamente na fala do narrador essa relação entre a natureza preexistente e que vai sendo transformada em civilização. Assim, em seus minutos finais, pode-se ouvir a seguinte locução:

As vastas extensões antes virgens e mudas sofreram uma transformação completa. Em menos de dois anos, brota do chão, como milagre da natureza, uma cidade nova em folha, que vai regurgitar de vida, marcando um novo passo no desenvolvimento do país. Brasília é produto de esforços reunidos: o empenho do governo, o amor de uma multidão de pioneiros entre administradores, técnicos e operários e, antes de tudo, a confiança de que se está criando as bases de uma nova civilização. ${ }^{4}$

As imagens veiculadas neste cinejornal apresentam um contraste expressivo entre a cidade sendo construída, em primeiro plano, e o plano de fundo sempre "manchado de desertos". ${ }^{2}$ Logo no início deste mesmo cinejornal, o objetivo é apresentar a inauguração da Rodovia Brasília-Anápolis. O contraste entre a modernidade que chega com a estrada com as áreas adjacentes que aparecem como plano de fundo chamam a atenção e esgarçam tanto a modernidade que chega quanto o sertão que se vai. A locução do narrador privilegia a questão do desenvolvimento e da modernidade que a Rodovia Brasília-Anápolis trará, o que contrasta violentamente com as imagens de uma vastidão e de um horizonte indeléveis. ${ }^{6}$

\footnotetext{
4 Cinejornal Brasília n 10. - Alvorada Filmes/Novacap - Duração 10’.

5 Cinejornal Brasília no 10 - minuto 4:50.

6 Cinejornal Brasília no 10 - minuto 3:50.
} 
$\mathrm{O}$ antes veiculado por esses cinejornais, o passado apresentado remete sempre a um espaço sertão. A semântica atribuída a esse sertão é polissêmica, acompanhando o imaginário do sertão ao longo da história brasileira: é o paraíso, é o purgatório, é o inferno. Como paraíso, Brasília acentuaria ainda mais a autenticidade do Brasil; como purgatório e inferno, sua construção significaria a redenção do povo brasileiro.

Uma das principais referências históricas do Brasil - para muitos, nossa certidão de nascimento - é justamente um documento que nos olha do exterior: a Carta de Pero Vaz de Caminha. Sua apresentação das terras encontradas pelos portugueses faz referência a aspectos tanto do litoral quanto do sertão.

(...) Esta terra senhor, me parece que da ponta que mais contra o sul vimos até outra ponta que contra o norte vem, de que nós deste porto houvemos visto, será tamanha que haverá nela bem vinte ou vinte e cinco léguas por costa. Tem, ao longo do mar, nalgumas partes, grandes barreiras, delas vermelhas, delas brancas; e a terra por cima toda é chã e muito cheia de grandes arvoredos. De ponta a ponta, é tudo praia calma, muito chã e muito formosa. Pelo sertão nos pareceu, vista do mar, muito grande, porque a estender os olhos, não podíamos ver senão terra com arvoredos, que nos parecei muito longa...(CAMINHA, 1943: 239-240)

Este sertão descrito por Caminha aparece representado em vários cinejornais do período: é recorrente a referência a uma Brasília "terra dadivosa, em que se plantando tudo dá"?

Nas páginas finais dos primeiros números da Revista Brasília, pode-se aferir também o uso de fotografias que mostram um sertão paradisíaco com árvores copadas, rios encachoeirados, dentre outras imagens que nos remetem à diacronia da palavra sertão significando, naquelas páginas, um Paraíso Terreal. Deve-se lembrar que a existência de água em profusão e o clima ameno são símbolos firmados na semântica do Paraíso. É Euclides da Cunha que afirma que o Rio Amazonas havia se convertido em

(...) mundo maravilhoso. (...) A própria superfície lisa e barrenta era mui outra. Porque o que se me abria às vistas desatadas naquele excesso de céus por cima de um excesso de águas, lembrava [...] uma página inédita e contemporânea do Gênesis.(... $)^{8}$

As imagens apresentadas nas fotografias do período da construção de Brasília, assim como nos filmes e nos cinejornais produzidos no período ${ }^{9}$, nos remetem às sensações de tranquilidade, abundância, frescor. Essa terra dadivosa, sonhada e profetizada por Dom Bosco em 1883 existiria entre os paralelos $15^{\circ}$ e $20^{\circ}$. Seria uma civilização em terras onde escorreria leite e mel. Esse é um dos temas presentes no cinejornal produzido pela Agência Nacional e intitulado Brasília Profecia de São João Bosco. Esse filme começa apresentando uma placa em que se encontra reproduzido um texto sobre a profecia de Dom Bosco.

Profecia de São João Bosco (30 de agosto de 1883)

Entre o paralelo $15^{\circ}$ e $20^{\circ}$, em um sítio onde se formava um lago, surgirá a Grande Civilização, a Terra Prometida, donde manam leite e mel. Uma inconcebível riqueza se estabelecerá. Essas coisas sobreviverão na $3^{a}$ geração.”

Brasília é um sonho secular que está surgindo em ritmo febril como na maravilhosa visão profética de São João Bosco. Simboliza esplendidamente o dinamismo, a inteligência e o patriotismo do homem brasileiro. ${ }^{10}$

A S.S.S. Produções, contratada pela Novacap, produziu pelo menos dois cinejornais cujo tema era exclusivamente "A produção e o abastecimento em Brasília." 11 . Neles, aparecem imagens de jardins com flores, aspectos de cachoeiras e, na sequência, imagens de canteiros de hortaliças, com toda a produção hortifrutigranjeira das áreas do entorno do que viria a ser Brasília.

Essa semântica paradisíaca para o sertão está presente em uma parte significativa do repertório de textos e imagens que tiveram como fonte os viajantes estrangeiros que se embrenharam pelos sertões do Brasil, desde a chegada dos portugueses a essas terras até fins do século 19.

\footnotetext{
7 “Brasília: profecia de Dom Bosco" - Agência Nacional - minuto 6:30.

8 Discurso de posse de Euclides da Cunha na Academia Brasileira de Letras, cadeira n 7 (18 de dezembro de 1906).

9 Cinejornal "Barragem Saia Velha” e Cinejornal "As Primeiras Imagens de Brasília” - Minuto 4:00.

10 Brasília - Profecia de São João Bosco. Produção Agência Nacional - Duração 7 minutos.

11 São os cinejornais da Novacap de números 21 e 22. Ambos com 10 minutos de duração cada.
} 
Essa visão paradisíaca das terras americanas era proveniente de diferentes imaginários europeus. Um dos elementos desse imaginário associa-se ao fato de que a pouca dadivosa natureza europeia era um sinal das consequências do Pecado Original e da natureza decaída do homem a partir de então. Sobre a degenerescência dela decorrente, Keith Thomas nos fala:

O Jardim do Éden era um paraíso preparado para o homem, no qual Deus conferiu a Adão o domínio sobre todas as coisas vivas (Gênesis, I, 28). No princípio homens e bestas conviveram pacificamente. Os homens provavelmente não eram carnívoros e os animais eram mansos. Mas com o pecado e a Queda, a relação se modificou. Ao rebelar-se contra Deus, o homem perdeu o direito de exercer o domínio fácil e inconteste sobre outras espécies. A terra degenerou. Espinhos e cardos nasceram onde existiam apenas flores e frutos. O solo fez-se pedregoso e árido, tornando-se necessário um trabalho árduo para seu cultivo. (THOMAS, 1988: 22)

A necessidade de trabalho que a natureza europeia requeria era, para os católicos europeus dos Tempos Modernos, a antítese do Paraíso, encontrado na natureza dadivosa das terras americanas.

De que se trata esse Paraíso? Um jardim perfeito com vegetação e animais dóceis, clima ameno que muitos europeus afirmavam ter encontrado em suas viagens às terras americanas, características que estão presentes nos discursos sobre a construção da nova capital.

Essa narrativa sobre o Brasil pode ser encontrada em diversas versões e em diferentes épocas constituindo o que Marilena Chaú chama de “imagem mítica fundadora”. Segundo ela, pode-se encontrar essas imagens

(...) na obra de Rocha Pita, que afirma explicitamente ser aqui o Paraíso Terrestre descoberto, no livro de Afonso Celso, nas poesias nativistas românticas, na letra do Hino Nacional, na explicação escolar da bandeira brasileira e nas poesias cívicas escolares como as de Olavo Bilac. Compreendemos agora o sentido mítico do auriverde pendão nacional. De fato, sabemos que, desde a Revolução Francesa, as bandeiras revolucionárias tendem a ser tricolores e são insígnias das lutas políticas por liberdade, igualdade, fraternidade. A bandeira brasileira é quadricolor e não exprime o político, não narra a história do país. É um símbolo da natureza. É o Brasil-jardim, o Brasil-paraíso. (CHAUÍ, 2001: 62)

Não é outra a narrativa daqueles anos da construção de Brasília. As palavras são do cardeal de São Paulo Dom Carlos Carmelo Vasconcelos Mota na cerimônia da Primeira Missa rezada no Planalto Central em 3 de maio de 1957:

(...) O cenário é todo esse Brasil imenso, aqui presente na personalização dos seus grandes filhos e aqui representado por esse panorama telúrico ainda virgem e por este horizonte visual ilimitado, e dilatado ainda pela nossa fantasia até nos confins do território nacional através de seus oito e meio milhares de quilômetros quadrados. [...] Foi feita pelo senhor toda essa maravilha da natureza que neste planalto os nossos olhos contemplam embevecidos.(...)

\section{E conclui:}

(...) Na Bíblia se lê como plantou Deus no meio do Paraíso terreal a miraculosa árvore da vida. Brasilia é a árvore da vida nacional providencialmente plantada no planalto central de nossa Pátria. Que as bênçãos de Deus e da Virgem Mãe de Deus façam com que Brasília cresça, floresça e frutifique em perene primavera da vida nova do Brasil. Incipit vita nova. (REVISTA BRASÍLIA, 1957: 13-14)

A associação entre as terras brasileiras e o paraíso ressaltou a natureza como uma de nossas características identitárias. Reiterando esta dimensão, Dr. Antônio Pimentel, membro da Missão Cruls, define assim a região do Planalto Central brasileiro:

É exuberante a fertilidade do solo; a salubridade proverbial; grande abundância de excelente água potável; rios navegáveis; extensos plainos sem interrupções importantes; soberbas madeiras de construção de suas grandes florestas; abundância de preciosos minerais e essências diversas; elevação do terreno determinando um menor grau de secura atmosférica e uma temperatura mais fresca do que a primeira vista se poderia supor, em face da sua latitude geográfica; tudo, enfim, que tem as mais estreitas relações com os progressos materiais de uma grande cidade, e com o bem estar de seus habitantes. (CRULS, 2003: 238) 
Outro exemplo de sobrevivência e de releitura desse espaço-sertão-Brasillia associado a esse imaginário do Mundo Novo e do Paraíso é o samba de José Rosas com Jorge Veiga do ano de 1958 (grifo meu):

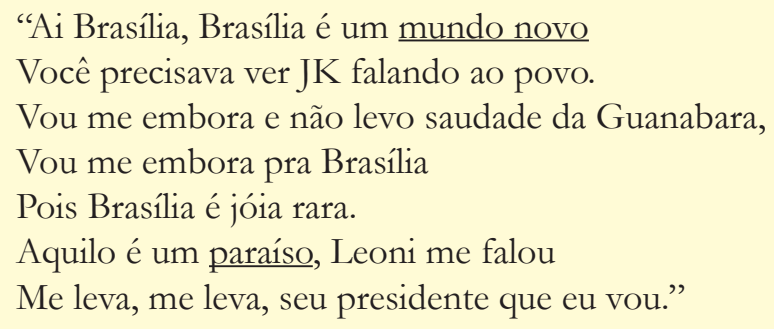

Juscelino Kubitschek também associa Brasília à Terra de Promissão em inúmeras ocasiões. Nesta, que reproduzo abaixo, o motivo é por oferecer uma alternativa de vida digna a todos os brasileiros:

Divulgando-se a notícia de que havia trabalho para todos em Brasília, avolumavam-se cada semana as levas de trabalhadores que lá chegavam. Vinha gente de todas as regiões do país. Era uma verdadeira torrente humana, que os caminhões canalizavam para o Planalto. Pobres de todas as latitudes em busca da Terra da Promissão. (KUBITSCHEK, 1957: 81)

A imagem da viagem é igualmente recorrente nos filmes produzidos ao longo do período da construção de Brasília. Chamo a atenção especialmente para o filme $O$ Bandeirante, produzido por Jean Manzon ${ }^{12}$. Nele, por volta do terceiro minuto, apresentam-se imagens de "caravanas de candangos (que) marcham para o Planalto Central" "13, como a locução faz crer. A música de fundo, impactante, é de autoria de Heitor Villa Lobos ${ }^{14}$. Há que se ressaltar, também, que as imagens são grandiosas: as tomadas em close dos candangos ou da realização do seu trabalho produzem um impacto visual que gera empatia do público com o esforço dos brasileiros para a construção da cidade. Esse padrão visual, em close e em grande formato, já era utilizado nas revistas e no cinema desde os anos 30 e estimulava a visão e a observação do público e dos leitores.

As imagens fotográficas também trazem o registro da chegada dos candangos para participar da construção de Brasília, atendendo ao chamado patriótico. Pode-se comparar tal odisseia ao purgatório, a uma passagem cujo objetivo é o regresso aos fundamentos de nossa história, ao interior, ao coração do país onde o "Brasil é mais Brasil". Juscelino Kubitschek afirmou que seu governo tinha a consciência que estava empreendendo

(...) a continuação de uma viagem que se iniciou com a chegada da frota de Cabral à Bahia, que prosseguiu com Mem de Sá para o Rio de Janeiro, que se alargou imponente na caminhada das Bandeiras e que agora, para alta e merecida honra de minha vida, retomo com o pensamento na integração do Brasil em si mesmo para a posse do povo brasileiro do seu próprio e imenso território. (REVISTA BRASÍLIA, 1957: 01)

E dá continuidade ao tema da viagem mais adiante, nessa mesma mensagem, avaliando que esse empreendimento é nada mais nada menos do que “(...) o prosseguimento da viagem da nacionalidade até Brasília." (Idem.)

Da mesma forma que a serpente habita o Paraíso (CHAUí, 2001: 66), o sertão, ao ser significado como purgatório, adquire sua carga contrária, de redenção, como se todo o sofrimento nos levasse a alcançar o Reino dos Céus. (DEBS, 2007: 120) Como o Cristianismo postula, sofra na terra para conseguir entrar no Reino dos Céus: esses são os bem-aventurados. É Jacques Le Goff que nos instrui:

12 Jean Manzon produziu mais de 700 documentários de curta-metragem para exibição em salas de cinema; muitos deles eram resultado de encomendas feitas ou por empresas ou pelo próprio governo. Jean Manzon, ao chegar ao Brasil, trabalhou inicialmente no Departamento de Imprensa e Propaganda (DIP) no governo Vargas; até 1952, sua principal ocupação foi a de fotógrafo da revista O Cruzeiro, até que, a partir desta data, montou sua própria produtora cinematográfica.

13 Filme $O$ Bandeirante. Produção Jean Manzon, minuto 3:00.

14 Heitor Villa Lobos compôs a música apresentada neste trecho do filme para a produção cinematográfica de Hollywwod intitulada "A Flor que não morreu" (1959), do diretor Mel Ferrer. 
O deserto é efetivamente um espaço ambiguidade: o monge encontra lá o demônio de um modo que pode dizer-se inevitável, porque o demônio no deserto está em sua casa; mas o monge encontra também no deserto, de certo modo, o Deus que lá veio procurar. A noção de deserto oscila entre uma concepção paradisíaca e uma concepção de prova. (LE GOFF, 1990: 41)

Mas houve igualmente outra ressignificação do vocábulo sertão: nas palavras de Juscelino e de tantos outros, Brasília era em enfrentamento, um problema, era uma "guerra redentora”"15 “(...) estonteante, patriótica batalha [...] cuja vitória está marcada para o dia 21 de abril de 1960." ${ }^{16}$ Nos jornais como O Globo, Correio da Manhã e Tribuna da Imprensa e todos os veículos de imprensa da rede dos Diários Associados, as críticas eram mais contundentes e as fotografias foram um outro campo de batalha, numa verdadeira guerra de imagens na mídia impressa. São inúmeras as reportagens que exibiam fotografias tiradas das obras que reforçavam a ideia de sertão como ausência de civilização. Uma delas se intitulava "Prédio do Congresso" e tinha como segunda legenda: "dentro do mato". (Jornal Tribuna da Imprensa, 17/02/1960)

Em Grande Sertão - Veredas, Guimarães Rosa afirma que o “(...) sertão é onde manda quem é forte, com as astúcias. Deus mesmo quando vier, que venha armado!” Ou ainda, como na música de Fagner “(...) Pulsando num segundo letal, no Planalto Central, onde se divide o bem e o mal"17.

Alguns jornais da época da construção de Brasília, cujas linhas editorias eram contrárias à transferência da capital, expressavam esse imaginário do sertão como uma terra sem lei. O jornal O Globo relaciona diretamente certas práticas vigentes, naquele contexto, à ausência de civilização:

Ambiente de Jagunçada e Prepotência em Brasilia (...) Ou Brasília começa, desde já, a civilizar-se, ou não suportaremos, por mais tempo esse ambiente de jagunçada e prepotência que favorece alguns poderosos em detrimento dos trabalhadores. Que a voz da imprensa moralize Brasília (...) a Novacap, encarregada de manter inclusive o policiamento da futura capital do país ... está investindo na função de policial indivíduos completamente desprovidos de condições para tanto, analfabetos, pode afirmar-se, truculentos, e que estão cometendo uma série de arbitrariedades. (O GLOBO, $20 / 05 / 1958)$

Vejamos outro trecho do jornal A Hora de 14 de junho de 1958 que também abordava a questão:

Os criminosos de Brasília são remetidos para a cidade de Luiziânia. Afirma-se que presos em flagrante e enviados para aquela comarca no dia seguinte aparecem tranquilos nas ruas da Cidade Livre, em colóquio com a polícia. Esta é a chamada guarda da Novacap. Tem 51 integrantes, dos quais apenas três são goianos e seis mineiros. O restante é composto de nordestinos. Ganha, cada um 5 mil cruzeiros, além de adicionais. Extremamente violenta encaminha quase todos os dias as suas vítimas para o hospital e dizem, por brincadeira, naturalmente, que no exame de seleção o comandante - um coronel reformado da polícia carioca - exige apenas que o candidato levante um saco de 70 quilos para provar se tem ou se não tem força. Um dos últimos atos violentos da guarda da Novacap foi o espancamento de um trabalhador. Acabaram furando-lhe os olhos e ficou por isso mesmo. (RIBEIRO, 2008: 56-57)

Ora, se o sítio escolhido para a construção da nova capital precisava encarnar o significado do sertão-atraso, do sertão-inferno era para que Brasília pudesse ser o símbolo da modernidade, do progresso, da civilização. Como assevera Joanildo Buriti, “(...) no Brasil, não há modernidade sem sertão.

No caso de Brasília, expressão do modernismo arquitetônico, a dissociação entre cidade e natureza se faz ainda mais presente, afinal, quanto menor a força da natureza sobre os homens, mais nos aproximamos da civilização e nos afastamos da barbárie. Em programa da rádio Mayring Veiga, denominado "Parada Nacional", que abordava aspectos da construção de Brasília, a fala do locutor realiza o conteúdo moderno da nova capital ao associar a imagem do Rio de Janeiro à natureza em oposição à moderna Brasília.

Nesse colosso universal, toda essa enorme massa de terra, que se distribui por 5 regiões da América do Sul é o território brasileiro (...) E este pontinho aqui, mais para o sul e para o leste, a orla marítima do Brasil, é a nossa cidade de São Sebastião do Rio de Janeiro, com a sua natureza, onde tudo desafia a imaginação do homem, que a escolheu para

15 Filme: “As Primeiras Imagens de Brasília." - Duração - 10'.

16 Filme "Brasília Terra de Todos Nós" - Duração 15”- minuto: 4:00

17 Música de Fagner "Cavalo-ferro" interpretada por Ednardo. 
capital da República dos Estados Unidos do Brasil. (...) Capital da República até o dia 21 de abril de 1960, quando por força do decreto (...) cederá as honras e as responsabilidades da sede do Governo Federal a Brasília, cidade planejada, feita pela mão do homem, em pleno coração do território, no Planalto Goiano, que espera receber o impulso dos brasileiros vindos de todos os quadrantes, para possuir de fato, a terra, ansiosa por se entregar ao trabalho do homem, que, como um conquistador apaixonado vai terminar o longo noivado dos brasileiros com as riquezas do Brasil central e com o progresso do país. Verdadeira marcha para o Oeste. (RODRIGUES, 1990: 70)

Procurei demonstrar que a transferência da capital do país para o interior de Goiás não foi um processo simples. Estava-se decidindo para onde iria a capitalidade da nação e, consequentemente, a identidade de todos nós. Gerson de Macedo Soares apresenta de forma bastante contundente o problema:

Com a ida da Capital Federal para o interior, lá para o planalto goiano, construída Brasília, este atual Distrito Federal que vai ser? - Estado autônomo? Território? Município de outro Estado? - De qualquer forma, passará a ser província ou parte da Província.

Brasília capital, seus filhos e habitantes passarão a ser os Senhores Federais, os da Corte, como se dizia no Império, os da Capital Federal, depois de novembro de 1889. E os outros todos, entre os quais os filhos deste atual Distrito Federal? - Ah! Aí é que está! Isso é o que me invoca! Os atuais filhos do atual Distrito Federal, isto é, os cariocas, que já foram da Corte e hoje ainda são Distrito Federal, passarão a ser ... provincianos! Sim, senhor, no duro - Pro - vin $-\mathrm{ci}-$ anos!

E é isso que me apoquenta e me invoca: eu também, carioca da gema, passar a ser Provinciano depois de ter nascido Federal! Ui! (SOARES, 2008: 222)

Defendo, portanto, que práticas que envolveram o uso do vocábulo sertão naqueles anos da construção de Brasília e as representações que engendraram, estiveram profundamente associadas à questão da identidade da nação, inclusive porque manipularam temas e questões muito caros a todos nós brasileiros como o território, o mito do Brasil Paraíso, a dicotomia dos dois Brasis: um no sertão e outro no litoral. Acredito que o peso da semântica da palavra sertão, estabelecida na diacronia de seus múltiplos usos, recuperados pelo Governo JK, estabeleceram para aquele lugar Brasília uma carga semântica tal, que impediu que Brasília representasse, naqueles anos subsequentes a sua construção, a capitalidade da nação.

\section{Referências bibliográficas}

ALVIM, Clara de Andrade. (coord.) Os Cine-jornais sobre o período de construção de Brasília. Brasília: MEC - SEC - Sphan/pró-Memória, s/d.

BIZELLO, Maria Leandra. Entre fotografias e fotogramas: a construção da imagem pública de Juscelino Kubitscheck. Campinas, Unicamp, 2008 (Tese de Doutorado).

CAMINHA, Pero Vaz . Carta de Pero Vaz de Caminha a D. Manuel datada de Porto Seguro em 1 de maio de 1500. In: CORTESÃO, Jaime (org). A carta de Pero Vaz de Caminha. Rio de Janeiro, Livros de Portugal, 1943.

CHAUÍ, Marilena. Brasil. Mito Fundador e Sociedade Autoritária. São Paulo: Fundação Perseu Abramo, 2001.

CRULS, Luiz. Relatório Cruls: Relatório da Comissão Exploradora do Planalto Central do Brasil. Brasília: Senado Federal, 2003.

DEBS, Sylvie. Cinema e Literatura no Brasil. Os Mitos do Sertão: emergência de uma identidade nacional. Fortaleza: Interarte, 2007.

KUBITSCHEK, Juscelino. Por que construi Brasilia. Rio de Janeiro: Bloch Editores, 1975

LE GOFF, Jacques. O Maravilhoso e o Cotidiano no Ocidente Medieval. Lisboa: Edições 70, 1990,

MAIA, Paulo Roberto de Azevedo. Canal 100: a trajetória de um cinejornal. Campinas, Unicamp, 2006 (Dissertação de Mestrado). 
Artigos

MENEZES, Paulo. “O Nascimento do Cinema Documental e o processo não Civilizador.” In: MARTINS, José de Souza (org.) O Imaginário e o Poético nas Ciências Sociais. Bauru: Edusc, 2005.

NEIVA, Ivany Câmara. Imaginando a capital: cartas a JK (1956 - 1961) Brasília, UnB, 2008 (Tese de Doutorado).

NUNES, José Walter. Patrimônios Subterrâneos em Brasília. São Paulo: Annablume, 2005.

Revista Brasília. Rio de Janeiro: Novacap. n. 20, agosto, 1958.

RIBEIRO, Gustavo Lins. O Capital da Esperança. A Experiência dos Trabalhadores na Construção de Brasília. Brasília: Editora da Universidade de Brasília, 2008.

RICOEUR, Paul. Tempo e Narrativa. Campinas: Papirus, 1997.

RODRIGUES, Georgete Medleg. Ideologia, Propaganda e Imaginário Social na Construcão de Brasília. Brasília, UnB, 1990 (Dissertação de Mestrado).

SALLES, João Moreira. “A Dificuldade do Documentário.” In: MARTINS, José de Souza (org.) O Imaginário e o Poético nas Ciências Sociais. Bauru: Edusc, 2005.

SOARES, Gerson de Macedo. "Provinciano!” Jornal do Brasil. Rio de Janeiro, 28 de agosto de 1957. In: SANTOS, Michelle dos. A Construção de Brasilia nas tramas de imagens e memórias pela imprensa escrita (1956-1960). Departamento de História, Universidade de Brasília, 2008 (Dissertação de Mestrado).

THOMAS, Keith. O Homem e o Mundo Natural. São Paulo: Companhia das Letras, 1988. 